\title{
Zinc oxide nanoparticles inhibits quorum sensing and virulence \\ in Pseudomonas aeruginosa
}

\author{
Moustafa M Saleh ${ }^{1}$, Refa't A Sadeq ${ }^{2}$, Hemat K Abdel Latif ${ }^{3}$, Hisham A Abbas ${ }^{3}$, Momen Askoura ${ }^{3}$
}

1. Department of Microbiology and Immunology, Faculty of Pharmacy, Port Said University, Port Said 42515, Egypt.

2. Department of Microbiology and Immunology, Faculty of Medicine, Port Said University, Egypt.

3. Department of Microbiology and Immunology, Faculty of Pharmacy, Zagazig University, Egypt.

\section{Emails:}

Refa't ASadeq e-mail:refat.sadek@med.psu.edu.eg

-Hemat K Abdel Latif e-mail:hemat.a16@yahoo.com

-Hisham A Abbas e-mail: hishamabbas2008@gmail.com

-Momen Askoura e-mail:momenaskora@yahoo.com

\begin{abstract}
Background: Quorum sensing inhibitionis an advanced strategy that aims to interfere with bacterial cell-to-cell communication systems (quorum sensing), which regulate virulence factors production in Psendomonas aeruginosa, in order to overcome the globalcrisis of antimicrobial resistance.

Objectives: Study the potential quorum sensing inhibitory effect of Zinc oxide ( $\mathrm{ZnO})$ nanoparticlesin Pseudomonas aeruginosa and the impact on production of virulence factors.

Methods: Quorum sensing inhibitory effect of $\mathrm{ZnO}$ was evaluated by assessing its ability to reducePseudomonas aeruginosa virulence factors production; rhamnolipids, pyocyanin, pyoverdin, hemolysins, elastase and proteases. Furthermore, qRT-PCR was performed to determine $\mathrm{ZnO}$ inhibitory effect onQS-regulatory geneslasI, lasR,rhlI, rhlR, pqsA and pqsR that control virulence factors secretion. Moreover, mice survival test was conducted to investigate the influence of $\mathrm{ZnO}$ on Pseudomonas aeruginosa-induced mortality in vivo.

Results: $\mathrm{ZnO}$ revealed a statistically significant reduction in the production of QS-controlled virulence factors rhamnolipids, pyocyanin, pyoverdin, hemolysins, elastase and proteases. Furthermore, $\mathrm{ZnO}$ exhibited a significant decrease in the relative expression of QS-regulatory geneslasI, lasR,rhlI, rhlR,pqsA and pqsR. Additionally, ZnO significantly reduced the pathogenesis of Pseudomonas aeruginosa in vivo
\end{abstract}

Conclusion: $\mathrm{ZnO}$ nanoparticles can be used as a quorum sensing inhibitor in Psendomonas aeruginosa infections either as an adjuvant or alternative to conventional antimicrobials.

Keywords: Pseudomonas aeruginosa, $\mathrm{ZnO}$, quorum sensing, virulence inhibition.

DOI: https://dx.doi.org/10.4314/ahs.v19i2.28

Cite as: Saleh MM, Sadeq RA, Abdel Latif HK, Abbas HA, Askoura M. Zinc oxide nanoparticles inbibits quorum sensing and virulence in Pseudomonas aeruginosa. Afri Health Sci.2019;19(2): 2043-2055. https:/ / dx.doi.org/ 10.4314/ abs.v19i2.28

\section{Corresponding author: \\ Moustafa M Saleh, \\ Department of Microbiology \\ and Immunology, Faculty of Pharmacy, \\ Port Said University, Port Said 42515, Egypt \\ Telephone No.: (002)01225998747 \\ Fax No.: (002)06636406634 \\ Email: Mostafa.mohamed@pharm.psu.edu.eg}

\section{Introduction}

Pseudomonas aeruginosa (Ps. aeruginosa) is considered one of the most frequent opportunistic pathogens worldwide that can infect patients with severe medical conditions, particularly immunosuppressed patients. It is responsible for many nosocomial diseases including respiratory tract infections, urinary tract infections, burn and surgical wound infections ${ }^{1}$. The fast expansion of bacterial resistance to antibioticsmakes it urgent to discover new therapeutic agents in order to combat this issue ${ }^{2}$. 
In $P$ s. aeruginosa, bacterial cells communicatewith each other through a process known as quorum sensing (QS) which plays a major role in bacterial pathogenesis ${ }^{3}$. In Ps. aeruginosa, there are three major QS systems, lasI/R system, rhlI/R system and pqsA/R system which are interconnected together through signaling chemical molecules (autoinducers); oxododecanoyl-homoserine lactone (C12-HSL), butyryl-homoserine lactone (C4-HSL) and Pseudomonas quinolone-based intracellular signal (PQS) produced by bacterial cells. When chemical autoinducers reach a certain threshold, the quorum, they trigger the genes that regulate the production of virulence factorssuch as pyocyanin, pyoverdin, hemolysins, elastase and proteases $^{4-6}$.

Quorum sensing inhibitors are agents that disrupt QS systems in bacterial cells leading to a reduction of virulence factors production and suppression of virulence without interrupting the bacterial growth and so no or low resistance is anticipated to arise against these agents ${ }^{7}$. In the recent years, the advances accomplished in the field of nanotechnology resulted in an increase in the applications of nanoparticles in the medical sector andas a therapy for infectious diseases. Superior effectiveness on resistant strains of metal oxide nanoparticles such as Zinc oxide $(\mathrm{ZnO})$ and silver has been reported. $\mathrm{ZnO}$ nanoparticles were found to exert a potent antimicrobial activity and significantly reduced skin infections and inflammation in mice ${ }^{8-9}$.

The current study aimed to investigate the possible quorum sensing inhibiting activity of $\mathrm{ZnO}$ nanoparticles and their potential role in reducing QS-controlled virulence factors production and pathogenesis in Ps. aeruginosa.

\section{Materials and methods}

\section{Bacterial isolates and their identification}

Ps.aeruginosa PAO1 wild-type standard strain and five clinical isolates(Ps1, Ps2, Ps3, Ps4 and Ps5) were used in this study. Ps.aeruginosa PAO1 was provided from the stock culture collection of Microbiology and Immunology Department, Faculty of Pharmacy, Zagazig University. Clinical isolates were isolated from patients with burn and surgical wound infections admitted to Port Said General Hospital, Egypt. Clinical isolates were identified by Gram-stain, production of green pigmentson nutrient agar, growth on MacConkey agar, oxidase test, motility, growth on selective mediumcetrimide agar and the ability to grow at $42^{\circ} \mathrm{C}$ as stated by Koneman et $\mathrm{al}^{10}$.

\section{Media and chemicals}

Mueller-Hinton broth, nutrient agar, MacConkey agar, cetrimide agar, tryptone and yeast extract were purchased from (Oxoid, UK), ZnO nanoparticles, Tris-base andElastin Congo Red (ECR) from (Sigma, St. Louis, USA). Other chemicals were of pharmaceutical grade.

\section{Antibiotic susceptibility testing of the clinical iso- lates}

The antibiotic susceptibility testing for the clinical isolates was carried out using the disc diffusion technique as described by the Clinical Laboratory and Standards Institute (CLSI) ${ }^{11}$ against 10 anti-pseudomonal antibiotics including, aztreonam $30 \mu \mathrm{g}$ (ATM), piperacillin $100 \mu \mathrm{g}$ (PRL), ceftazidime $30 \mu \mathrm{g}$ (CAZ), cefepime $30 \mu \mathrm{g}$ (FEP), ciprofloxacin $5 \mu \mathrm{g}$ (CIP), levofloxacin $5 \mu \mathrm{g}$ (LEV), amikacin $30 \mu \mathrm{g}(\mathrm{AK})$, gentamicin $10 \mu \mathrm{g}(\mathrm{CN})$, colistin sulfate 10 $\mu \mathrm{g}(\mathrm{CT})$ and imipenem $10 \mu \mathrm{g}$ (IPM). The anti-pseudomonal discs were purchased from (Oxoid, UK).

\section{Determination of minimum inhibitory concentra- tion and investigating the effect of sub-inhibitory concentration of $\mathrm{ZnO}$ nanoparticles on bacterial growth}

The minimum inhibitory concentration (MIC) of $\mathrm{ZnO}$ nanoparticles was determinedby using the agar dilution method according to(CLSI ${ }^{11}$. Briefly, overnight bacterial cultures of the tested isolateswere diluted, each with Mueller-Hinton broth to reach a turbidity matching that of 0.5 MacFarland Standard and then with sterile saline to achieve a final concentration of $10^{7} \mathrm{CFU} / \mathrm{ml}$. Nutrient agar plates with different concentrations of $\mathrm{ZnO}(1,2,4$, $8,16,32$ and $64 \mathrm{mg} / \mathrm{ml}$ ) were prepared in addition to control plates without $\mathrm{ZnO}$. The plates' surfaces were inoculated with $1 \mu \mathrm{l}$ of the suspensions of the tested isolates and incubated overnight at $37^{\circ} \mathrm{C}$. The MIC was calculated as the least concentration of $\mathrm{ZnO}$ that prevented the visible growth of bacteria.

To ensure that $\mathrm{ZnO}$ sub-MIC that would be used in further experiments had no influence on bacterial viability, the effect of $1 / 4 \mathrm{MIC}$ of $\mathrm{ZnO}$ on bacterial growth was assessed following Nalca et $\mathrm{al}^{12}$. The tested isolates were incubated in Luria-Bertani (LB) broth (tryptone $10 \mathrm{~g}$, yeast extract $5 \mathrm{~g}$ and $10 \mathrm{~g}$ sodium chloride in $1000 \mathrm{ml}$ distilled $\mathrm{H} 2 \mathrm{O}$ ) with and without $1 / 4 \mathrm{MIC}$ of $\mathrm{ZnO}$ under the same conditions. After $24 \mathrm{~h}$ of incubation at $37^{\circ} \mathrm{C}$, the optical densities of $\mathrm{ZnO}$-treated and untreated cultures were 
measured at OD600 using spectrofluorometer (Biotek, USA).

The phenotypic effect of $\mathrm{ZnO}$ nanoparticles on QS-controlled virulence factors production

\section{Effect on rhamnolipids}

Rhamnolipids production, in the presence and absence of $\mathrm{ZnO}$, was assessed by oil spreading method according to Morikawa et $\mathrm{a}^{13}$. A thin oily layer was formed on the surface of water by addition of $20 \mu$ l of crude oil to 15 $\mathrm{ml}$ of distilled $\mathrm{H}_{2} \mathrm{O}$ in a Petri dish. Ten $\mu$ l of cell-free supernatants of the tested isolates with and without $1 / 4$ MIC of $\mathrm{ZnO}$ was added to the center of the oily layer. The diameters of the clear zones formed that are related to the biosurfactant activity and the amounts of rhamnolipids produced by the tested isolates were measured and compared.

\section{Effect on pyocyanin}

Pyocyanin determination was performed in King A medium (peptone $20 \mathrm{~g}, \mathrm{MgCl}_{2} 1.4 \mathrm{~g}$ and $10 \mathrm{~g} \mathrm{~K}_{2} \mathrm{SO}_{4}$ in 1000 $\mathrm{ml}$ distilled $\mathrm{H}_{2} \mathrm{O}$ ) according to Essar et $\mathrm{al}^{14}$. The tested isolates were grown in King A mediumwith and without $1 / 4$ MIC of $\mathrm{ZnO}$ for $48 \mathrm{~h}$ at $37^{\circ} \mathrm{C}$. Pyocyanin was extracted by addition of aliquots of $2.5 \mathrm{ml}$ of bacterial supernatants to $3 \mathrm{ml}$ chloroform followed by mixing with $1 \mathrm{ml}$ of $0.2 \mathrm{~N} \mathrm{HCl}$. The pigment in chloroform layer was measured at OD520 using spectrofluorometer (Biotek, USA).

\section{Effect on pyoverdin}

In order to estimate pyoverdin, the method of CoxandAdams ${ }^{15}$ was used. Overnight cultures of the tested isolatesin LB broth were prepared in the presence and absence of $1 / 4 \mathrm{MIC}$ of $\mathrm{ZnO}$ and then centrifuged at 10000 rpm for $10 \mathrm{~min}$. The cell-free supernatants were diluted to $1 / 10$ with $50 \mathrm{mM}$ Tris- $\mathrm{HCl}$ and $\mathrm{pH}$ adjusted to 7.4. The pyoverdin fluorescence in supernatants was measured at $460 \mathrm{~nm}$, where the samples were excited at 400 $\mathrm{nm}$ using spectrofluorometer (Biotek, USA).

\section{Effect on hemolysins}

Production of hemolysin was determined following the modified method ofDacheux et $\mathrm{al}^{16}$. Aliquots of $0.5 \mathrm{ml}$ of cell-free supernatants of tested isolates in LB broth with and without $1 / 4 \mathrm{MIC}$ of $\mathrm{ZnO}$ were mixed with $0.7 \mathrm{ml}$ of $2 \%$ sheep RBCs in saline followed by incubation at $37^{\circ} \mathrm{C}$ for $2 \mathrm{~h}$. After centrifugation of assay mixtures at 2500 rpm for 5 min to remove any cells, the released hemoglobin was measured at OD540 nm. Percentage lysis was calculated from the formula: $[\mathrm{X}-\mathrm{B} / \mathrm{T}-\mathrm{B}] \mathrm{x} 100$, where $\mathrm{B}$ is the negative control corresponding to RBCs in LB broth, $\mathrm{T}$ is the positive control corresponding to completely lysed RBCs with $0.1 \% \mathrm{SDS}$ and $\mathrm{X}$ is the $\mathrm{ZnO}$-treated or untreated isolates. The hemolytic activity percentage produced byZnO-treated isolates was compared to that produced by untreated isolates.

\section{Effect on elastase}

Elastase assay was evaluated according to Ohman et al ${ }^{17}$ using ECR. Briefly, an aliquot of $0.5 \mathrm{ml}$ of ECR solution $(10 \mathrm{mg} / \mathrm{ml})$ in Tris buffer $(\mathrm{pH} 7.0)$ was inoculated with $0.25 \mathrm{ml}$ of each cell-free supernatant of the tested isolates prepared in the presence and absence of $1 / 4$ MIC of $\mathrm{ZnO}$. The mixtures were left at $37^{\circ} \mathrm{C}$ for $6 \mathrm{~h}$ and then centrifuged at $10000 \mathrm{rpm}$ for $10 \mathrm{~min}$ to remove insoluble ECR pellets. The color of released ECR in supernatantswas measured at OD495 $\mathrm{nm}$ using spectrofluorometer(Biotek, USA).

\section{Effect on proteases}

The total proteases were estimated by the modified skim milk assayas described by El-Mowafy et $\mathrm{al}^{18}$. An aliquot of $0.5 \mathrm{ml}$ cell-free supernatant of each of the testedisolates prepared with and without $1 / 4$ MIC of $\mathrm{ZnOwasmixed}$ with $1 \mathrm{ml}$ of skim milk solution $(1.25 \%$ in distilled $\mathrm{H} 2 \mathrm{O})$ and incubated at $37^{\circ} \mathrm{C}$ for 30 minutes. The turbidities of assay mixtures were measured at OD600using spectrofluorometer as a measure of the proteolytic activity.

\section{Estimation of relative gene expression of QS-regu- latory genes using qRT-PCR}

For molecular determination of QS-regulatory genes,total bacterial RNA was extracted at the middle of the log phase,corresponding to OD600of $0.5-0.6$,from the tested strains cultivated overnight in $\mathrm{LB}$ broth at $37^{\circ} \mathrm{C}$ in presence and absence of $1 / 4 \mathrm{MIC}$ of $\mathrm{ZnO}$ using GeneJET RNA Purification Kit following the manufacturer instructions.Reverse transcription followed by qRT-PCR of QS-regulatory genes lasI, lasR, rhlI, rhlR, pqsA and pqsR was carried out using SensiFAST ${ }^{\text {TM }}$ SYBR ${ }^{\circledR}$ Hi-ROX One-Step Kit.StepOne Real-Time PCR thermal cycler utilizing primers illustrated in Table 1 was used to setup the qRT-PCR analysis. The relative expression values of QS-regulatory genes were normalized to the housekeep- 
ing gene rpoD and agarose gel electrophoresis was used to confirm the specific PCR amplification. The relative gene expression in $\mathrm{ZnO}$-treatedcultures was compared to their expression levels in untreated ones following the $2-\Delta \Delta$ Ct method ${ }^{19}$.

\section{Mice survival test}

The influence of $\mathrm{ZnO}$ on Ps. aeruginosa pathogenesis was assessed by the mice survival in vivo model following the method of Kim et $\mathrm{al}^{20}$. The ethical standards of Medical Research Center, Ain Shams University, Cairo, Egypt, where the experiment was conducted and the mice were provided, were followed in the animal study. An approximate cell density of $2.5 \times 10^{7} \mathrm{CFU} / \mathrm{ml}$ in phosphate-buffered saline (PBS) of Ps. aeruginosa PAO1 was prepared from overnight bacterial cultures in LB broth with and without $1 / 4$ MIC of $\mathrm{ZnO}$. Four random groups of three-weeks-old healthy female albino mice (Mus musculus) with the same weight were used, each comprising 10 mice. In Group 1, mice were injected intraperitoneallywith $100 \mu \mathrm{l}$ of $\mathrm{ZnO}$-treated bacteria in sterile PBS, while group 2 was injected with $100 \mu$ l of untreated bacteria. Two negative control groups are included also;group 3 miceare injected with $100 \mu \mathrm{l}$ of sterile PBS andgroup 4 mice were left uninoculated. All groups were kept with normal feeding and aeration at room temperature. The survival of mice in each group was recorded every day for 3 successive days. The results were calculated using Log-rank test,GraphPad Prism 5 and plotted using Kaplan-Meier method.

\section{Statistical analysis}

The influence of $\mathrm{ZnO}$ on Ps. aeruginosa QS-controlled virulence factors production was analyzed using GraphPad Prism 5 software package with One Way ANOVA according to Dunnet's or Tukey's Multiple Comparison Tests $<0.05$ or $\mathrm{P}<0.001$ for significance. Results were calculated as the means \pm standard errors of three biological experiments with three technical replicates each.

\section{Results}

\section{Identification of clinical isolates}

Ps. aeruginosa clinical isolates were identified from the following characters: they were Gram-negative rods and grew as non-lactose fermenters on MacConkey agar, they grew on cetrimide agar at $42^{\circ} \mathrm{C}$ and showed green pigmentation on nutrient agar, they were motile and oxidase positive.

Table 1 Primers used in qRT-PCR (El-Mowafy et $\mathrm{al}^{18}$ ).

\begin{tabular}{|c|c|c|c|}
\hline Gene name & Primer sequence & Annealing temp. & Amplicon size (bp) \\
\hline $\operatorname{ropD}\left(\mathrm{F}^{\mathrm{a}}\right)$ & 5'-CGAACTGCTTGCCGACTT-3' & $56^{\circ} \mathrm{C}$ & 131 \\
\hline $\operatorname{ropD}\left(\mathrm{R}^{\mathrm{b}}\right)$ & 5'-GCGAGAGCCTCAAGGATAC-3' & & \\
\hline $\operatorname{lasI}(\mathrm{F})$ & 5'-CGCACATCTGGGAACTCA-3' & $56^{\circ} \mathrm{C}$ & 176 \\
\hline $\operatorname{lasI}(\mathrm{R})$ & 5'-CGGCACGGATCATCATCT-3' & & \\
\hline $\operatorname{las} R(\mathrm{~F})$ & 5'-CTGTGGATGCTCAAGGACTAC-3' & $55^{\circ} \mathrm{C}$ & 133 \\
\hline $\operatorname{las} R(\mathrm{R})$ & 5'-AACTGGTCTTGCCGATGG-3' & & \\
\hline $\operatorname{rhlI}(\mathrm{F})$ & 5'-GTAGCGGGTTTGCGGATG-3' & $58^{\circ} \mathrm{C}$ & 101 \\
\hline $\operatorname{rhlI}(\mathrm{R})$ & 5'-CGGCATCAGGTCTTCATCG-3' & & \\
\hline $\operatorname{rhlR}(\mathrm{F})$ & 5'-GCCAGCGTCTTGTTCGG-3' & $58^{\circ} \mathrm{C}$ & 160 \\
\hline $\operatorname{rhlR}(\mathrm{R})$ & 5'-CGGTCTGCCTGAGCCATC-3' & & \\
\hline$p q s A(\mathrm{~F})$ & 5'-GACCGGCTGTATTCGATTC-3' & $58^{\circ} \mathrm{C}$ & 74 \\
\hline$p q s A(\mathrm{R})$ & 5'-GCTGAACCAGGGAAAGAAC-3' & & \\
\hline$p q s R(\mathrm{~F})$ & 5'-CTGATCTGCCGGTAATTGG-3' & $58^{\circ} \mathrm{C}$ & 142 \\
\hline$p q s R(\mathrm{R})$ & 5'-ATCGACGAGGAACTGAAGA-3' & & \\
\hline
\end{tabular}


Antibiotic susceptibility and resistance pattern of clinical isolates

The tested clinical isolates of $P$ s. aeruginos ashowed high resistance against the various antibiotics used in this study. They all were found to be multi-drug resistant (MDR). The full results of antibiotic susceptibility test are illustrated in Table 2.

Table 2 Antibiotic susceptibility pattern of the five clinical isolates

\begin{tabular}{|c|c|c|c|c|c|c|c|c|c|c|}
\hline $\begin{array}{l}\text { Antibiotics } \\
\text { Isolate No. }\end{array}$ & ATM & PRL & CAZ & FEP & CIP & LEV & AK & CN & CT & IPM \\
\hline Ps1 & S & I & R & R & R & R & R & R & R & R \\
\hline Ps2 & $\mathrm{I}$ & $\mathrm{R}$ & $\mathrm{S}$ & $\mathrm{R}$ & $\mathrm{R}$ & $\mathrm{R}$ & $\mathrm{R}$ & $\mathrm{R}$ & $\mathrm{R}$ & $\mathrm{R}$ \\
\hline Ps3 & $\mathrm{R}$ & $\mathrm{R}$ & $\mathrm{R}$ & $\mathrm{R}$ & $\mathrm{R}$ & $\mathrm{R}$ & $\mathrm{R}$ & $\mathrm{R}$ & $\mathrm{S}$ & $\mathrm{R}$ \\
\hline Ps4 & $\mathrm{R}$ & $\mathrm{R}$ & $\mathrm{I}$ & $\mathrm{R}$ & $\mathrm{R}$ & $\mathrm{R}$ & $\mathrm{R}$ & $\mathrm{R}$ & $\mathrm{S}$ & $\mathrm{R}$ \\
\hline Ps5 & $\mathrm{R}$ & $\mathrm{R}$ & $\mathrm{R}$ & $\mathrm{R}$ & $\mathrm{S}$ & $\mathrm{S}$ & $\mathrm{R}$ & $\mathrm{R}$ & $\mathrm{R}$ & $\mathrm{R}$ \\
\hline
\end{tabular}

Antibacterial activity of $\mathrm{ZnO}$ and growth inhibition assay

$\mathrm{ZnO}$ prevented the growth of tested Ps. aeruginosa isolates at a concentration of $8 \mathrm{mg} / \mathrm{ml}$ and $1 / 4 \mathrm{MIC}(2 \mathrm{mg} / \mathrm{ml})$ was selected to test the effect of $\mathrm{ZnO}$ against QS-controlled virulence factors.

The efficacy of $\mathrm{ZnO}$ on QS-controlled virulence factors could be due to its effect on the growth of Psendomonas isolates. To exclude this possibility, the effect of $1 / 4 \mathrm{MIC}$ of $\mathrm{ZnO}$ on bacterial growth was assessed by measuring the optical density of overnight culturesin LB broth at $600 \mathrm{~nm}$ and no statistically significant difference in the growth rate was found in the presence or absence of $\mathrm{ZnO}$ (Fig. 1).

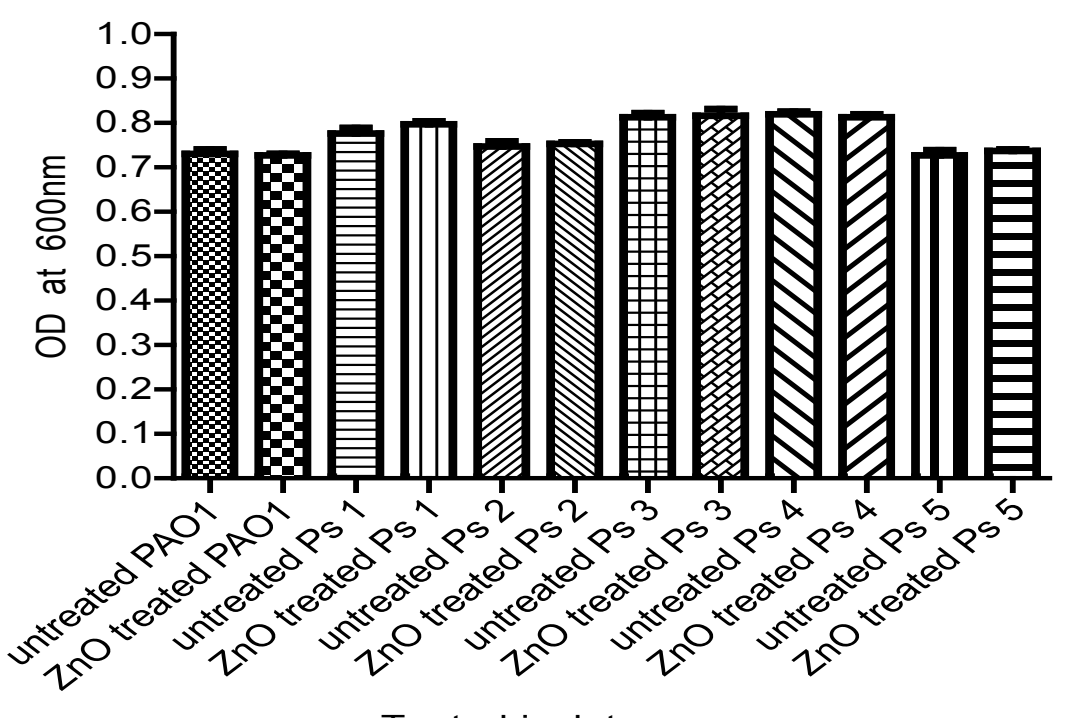

Tested isolates

Figure 1. The $\mathrm{OD}_{600}$ of Ps.aeruginosa isolates was measured after overnight incubation in $\mathrm{LB}$ broth with and without $1 / 4 \mathrm{MIC}$ of $\mathrm{ZnO}$. No significant difference was observed in the growth rates of $\mathrm{ZnO}$-treated and untreated isolates. 
$\mathrm{ZnO}$ inhibits rhamnolipids and pyocyanin production

$\mathrm{ZnO}$ could significantly reduce rhamnolipids production from $100 \%$ in untreated isolates to $30 \%, 28 \%, 22 \%$,
$35 \%, 21 \%$ and $31 \%$ in PAO-1, Ps1, Ps2, Ps3, Ps4 and Ps5 $\mathrm{ZnO}$-treated isolates respectively (Fig. 2a); while pyocyanin production was significantly decreased to $26 \%, 42 \%$, $33 \%, 33 \%, 47 \%$ and $27 \%$ in PAO-1, Ps1, Ps2, Ps3, Ps4 and $\mathrm{Ps} 5 \mathrm{ZnO}$-treated isolates respectively (Fig. 2b).

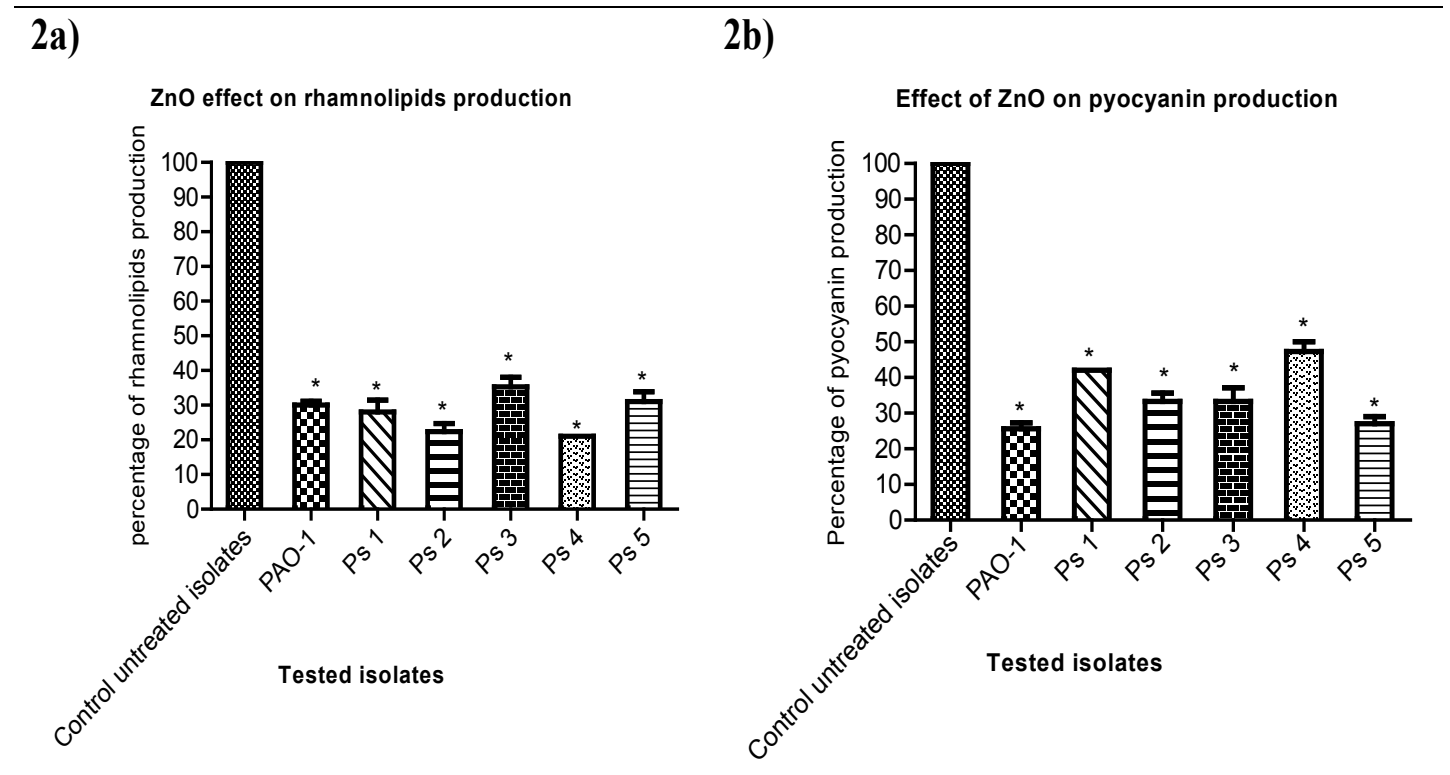

\begin{abstract}
Figure 2.(a) Rhamnolipids production reduction in $\mathrm{ZnO-treated} \mathrm{bacteria.} \mathrm{The} \mathrm{diameters} \mathrm{of} \mathrm{clear} \mathrm{zones} \mathrm{produced}$ by addition of the supernatants obtained after culturing in LB broth in the presence and absence of $1 / 4$ MIC of $\mathrm{ZnO}$ were measured. (b) Pyocyanin production reduction in $\mathrm{ZnO}$-treated bacteria. The absorbance of pyocyanin was measured at $520 \mathrm{~nm}$ in the supernatants obtained from the cultures in King A broth in the presence and absence of $1 / 4 \mathrm{MIC}$ of $\mathrm{ZnO}$. The data shown represent the means \pm standard errors of three biological experiments with three technical replicates each. *, significant $P<0.05$.
\end{abstract}

$\mathrm{ZnO}$ inhibits pyoverdin and hemolysins production $\mathrm{ZnO}$-treated cultures showed a remarkable decrease in pyoverdin production to $25 \%, 82 \%, 33 \%, 31 \%, 9 \%$ and $28 \%$ in PAO-1, Ps1, Ps2, Ps3, Ps4 and Ps5 ZnO-treated isolates respectively (Fig. 3a). Furthermore, hemolysins production was completely blocked in PAO-1 and Ps4 $(0 \%)$ and was decreased tomerely $3 \%, 3 \%, 6 \%$ and $2 \%$ in Ps1, Ps2, Ps3 and Ps5 ZnO-treated isolates respectively (Fig. 3b). 
3a)

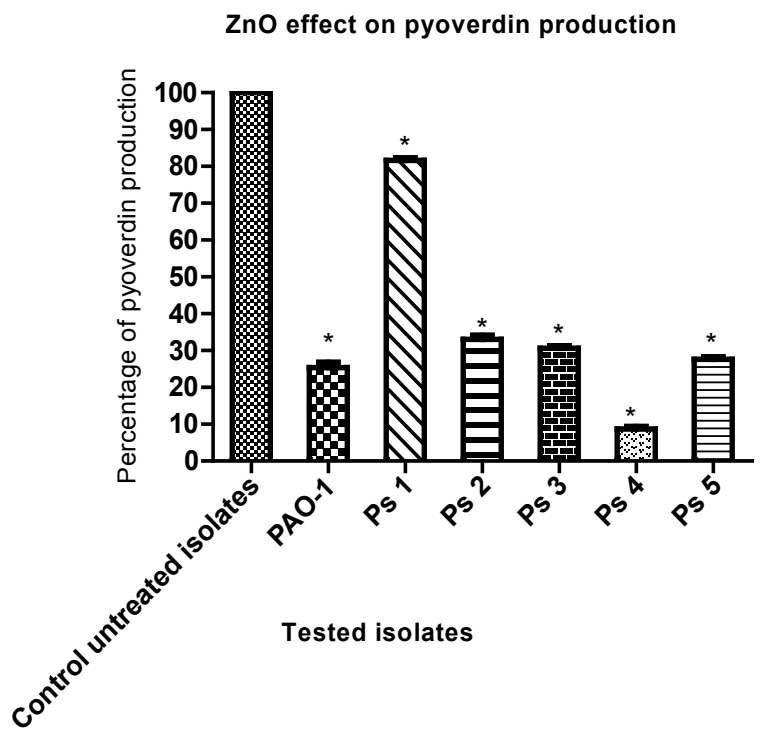

3b)

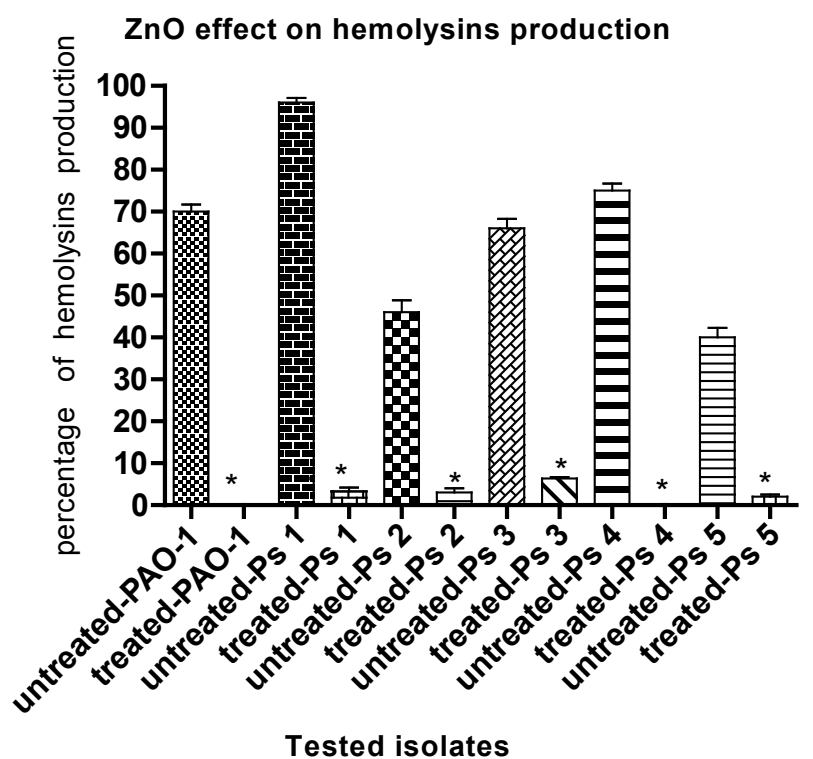

Figure 3.(a) Pyoverdin production reduction in $\mathrm{ZnO}$-treated isolates. Pyoverdinfluorescence was measured at $460 \mathrm{~nm}$ while the samples were excited at 400 nmafter overnight culture in LB broth in the presence and absence of $1 / 4 \mathrm{MIC}$ of $\mathrm{ZnO}$.(b) Hemolysin reduction in $\mathrm{ZnO}$-treated isolates. Absorbance of hemoglobin red color released by hemolysisofRBCs was measured at $540 \mathrm{~nm}$. The data shown are the means \pm standard errors of three biological experiments with three technical replicates each. *, significant $P<0.05$.

\section{$\mathrm{ZnO}$ inhibits elastase and proteases production}

Elastase production in the presence of $\mathrm{ZnO}$ was significantly diminished to $40 \%, 53 \%, 82 \%, 63 \%, 57 \%$ and $48 \%$ in PAO-1, Ps1, Ps2, Ps3, Ps4 and Ps5 ZnO-treated isolates respectively (Fig. 4a). Moreover, proteases production was significantly decreased to $38 \%, 52 \%, 41 \%$, $33 \%, 37 \%$ and $30 \%$ in PAO-1, Ps1, Ps2, Ps3, Ps4 and Ps5 $\mathrm{ZnO}$-treated isolates respectively (Fig. 4b).

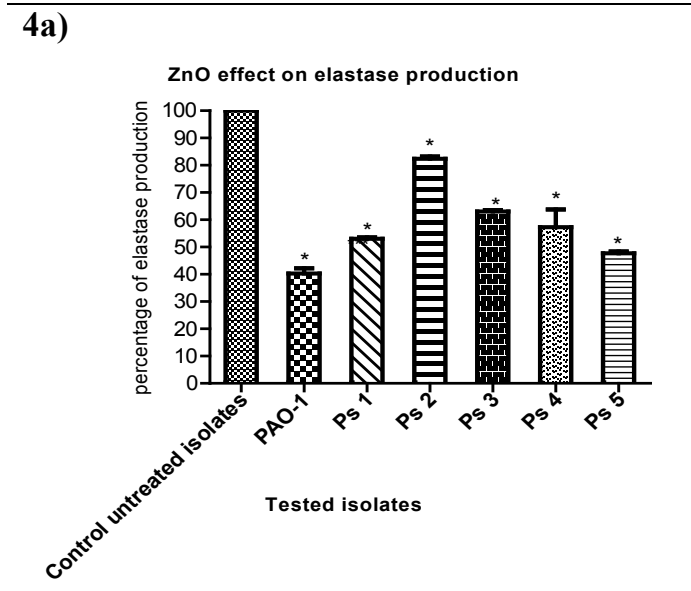

4b)

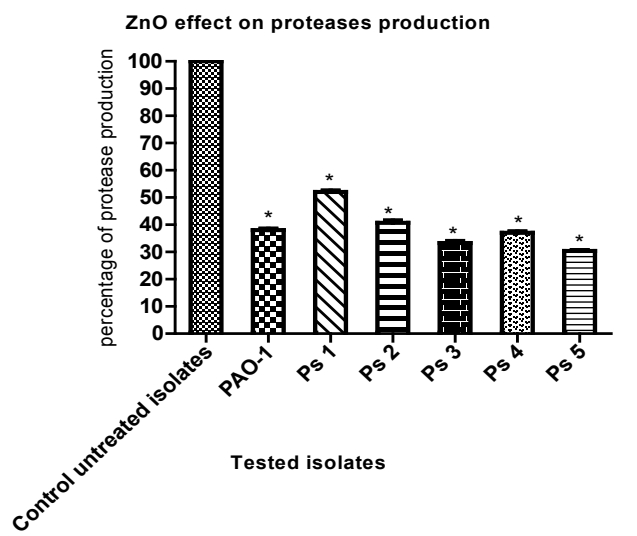

Figure 4.(a) Elastase production reduction in $\mathrm{ZnO}$-treated isolates. Absorbance at $495 \mathrm{~nm}$ was measured to show the effect of elastase on ECR after culture of bacteria in LB broth with and without $1 / 4 \mathrm{MIC}$ of $\mathrm{ZnO}$ for 6 h.(b) Proteases production reduction in $\mathrm{ZnO}$-treated bacteria. $\mathrm{OD}_{600}$ was measured following overnight culture of bacteria in LB broth with and without $1 / 4 \mathrm{MIC}$ of $\mathrm{ZnO}$ and incubation of supernatants with skim milk for $1 / 2 \mathrm{hr}$ at $37^{\circ} \mathrm{C}$. The data shown are the means \pm standard errors of three biological experiments with three technical replicates each. *, significant $P<0.05$. 
Estimation of relative gene expression ofQS-regulatory genes using qRT-PCR

The relative expression of the genes regulating virulence factors production was assessed in $\mathrm{ZnO}$-treated and un- treated strains and analyzed using the $2-\Delta \Delta \mathrm{Ct}$ method. The relative expression levels of lasI, lasR, rhlI, rhlR, pqsA and pqsR were significantly reduced under $\mathrm{ZnO}$ sub-MIC treatment (Figs. 5a, b, c, d, e and f), respectively.

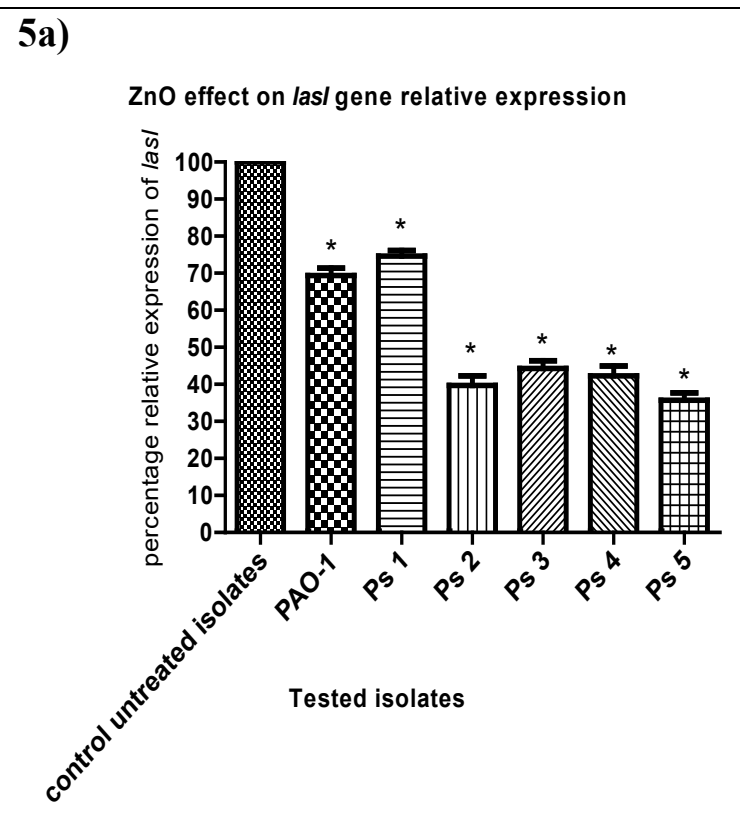

5b)

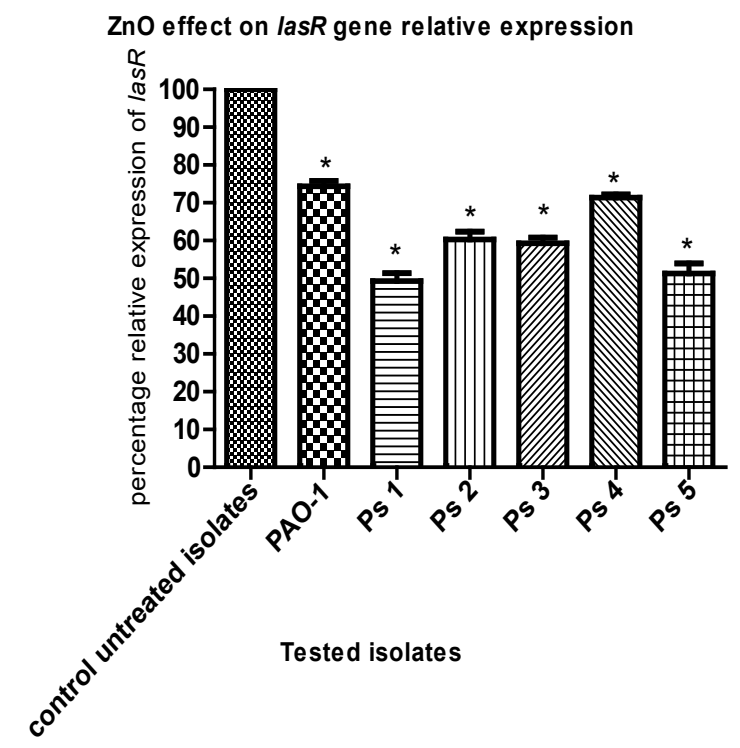

5c)

5d)
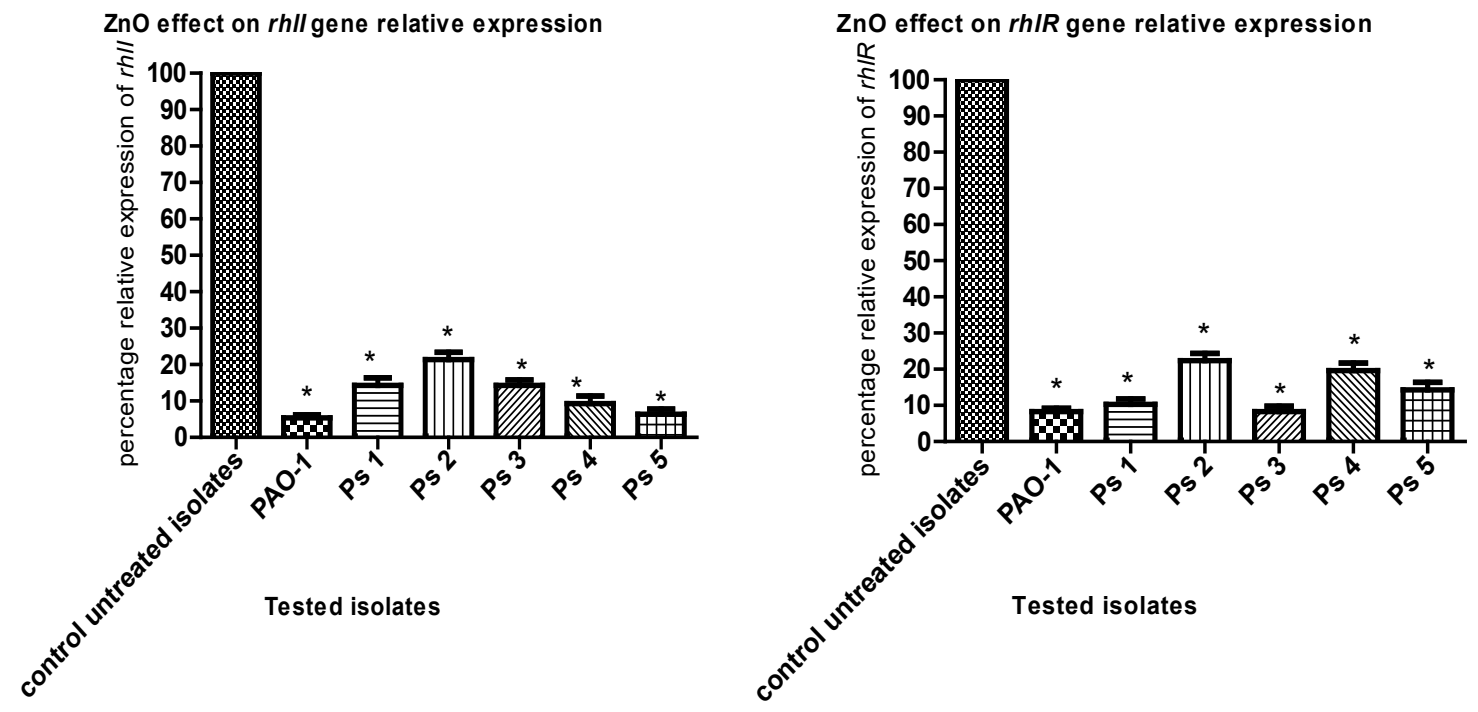
5e)

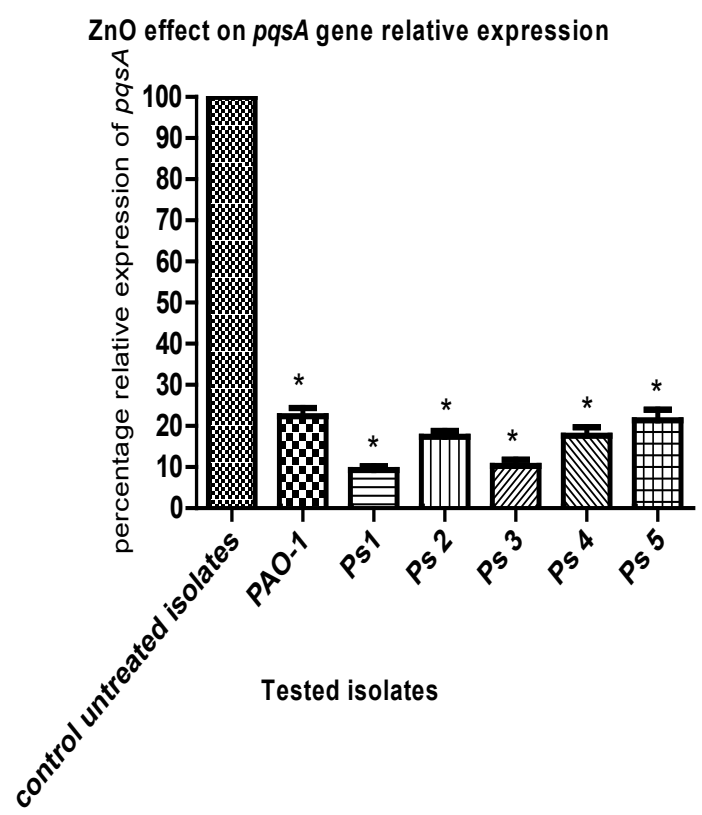

5f)

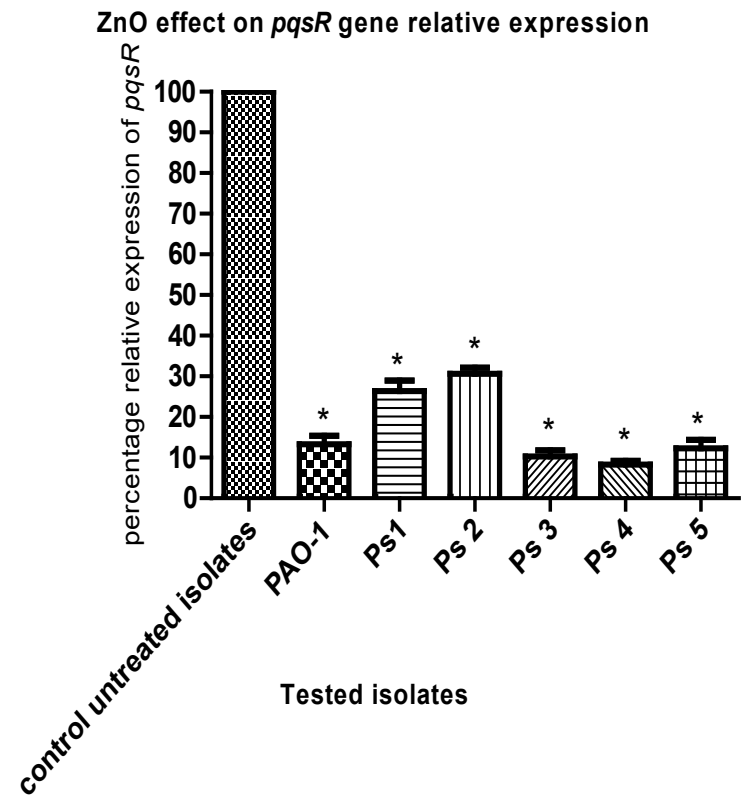

Figure 5. RT-qPCR showedreduced expressionof (a) lasI, (b) lasR, (c) rhlI, (d) rhlR, (e) pqsA and (f) pqsR in $\mathrm{ZnO}$-treated bacteria as compared to untreated ones.The data shown are the means \pm standard errors of three biological experiments with three technical replicates each. *, significant $P<0.05$.

The relative expression of lasI gene was significantly decreased from $100 \%$ in untreated isolates to $69 \%, 75 \%$, $40 \%, 44 \%, 42 \%$ and $36 \%$ in PAO-1, Ps1, Ps2, Ps3, Ps4 and $\mathrm{Ps} 5 \mathrm{ZnO}$-treated isolates respectively, and was also reduced to $74 \%, 49 \%, 60 \%, 59 \%, 71 \%$ and $51 \%$ in $\mathrm{PAO}-$ 1, Ps1, Ps2, Ps3, Ps4 and Ps5 ZnO-treated isolates respectivelyfor lasRgene as compared to untreated strains. Moreover, the relative expression of rhlI gene wassignificantly reduced to $5 \%, 14 \%, 21 \%, 14 \%, 9 \%$ and $6 \%$ in PAO-1, Ps1, Ps2, Ps3, Ps4 and Ps5 ZnO-treated isolates respectively, while rhlR gene relative expression was dropped to $8 \%, 10 \%, 22 \%, 8 \%, 20 \%$ and $14 \%$ in PAO-1, Ps1, Ps2, Ps3, Ps4 and Ps5 ZnO-treated isolates respectively. Furthermore, the relative expression of pqsA wassignificantly diminished to $22 \%, 9 \%, 17 \%, 10 \%, 18 \%$ and $21 \%$ in PAO-1, Ps1, Ps2, Ps3, Ps4 and Ps5 ZnO-treated isolates respectively and the relative expression of pqsR gene was also reduced to $13 \%, 26 \%, 31 \%, 10 \%, 8 \%$ and $12 \%$ in PAO-1, Ps1, Ps2, Ps3, Ps4 and Ps5 ZnO-treated isolates respectively.
Specific PCR amplification products of the tested genes lasI, lasR, rhlI, rhlR, pqsA and pqsR were confirmed by agarose gel electrophoresis (Figs. 6a, b, c, d, e and f) respectively.

$\mathrm{ZnO}$ decreased pathogenesis of Ps. aeruginosa in vivo In mice survival test shown in (Fig. 7), mice injected with positive control (untreated) Ps. aeruginosa began to die after $24 \mathrm{~h}$ and only $20 \%$ of mice in this group were still alive at the end of the experiment. Importantly, at an infectious dose of approximately $2.5 \times 10^{7} \mathrm{CFU}$, mice injected with bacteria treated with $\mathrm{ZnO}$ showed a significantly higher survival rate as compared to positive control bacteria as all mice in this group remained alive at the end of the experiment; a result similar to that of the negative control groups in which no mice in these groups died at the end of the experiment. Our resultssuggest a protective role of $\mathrm{ZnO}$ nanoparticles against Ps.aeruginosa pathogenesis and virulence in mice. 


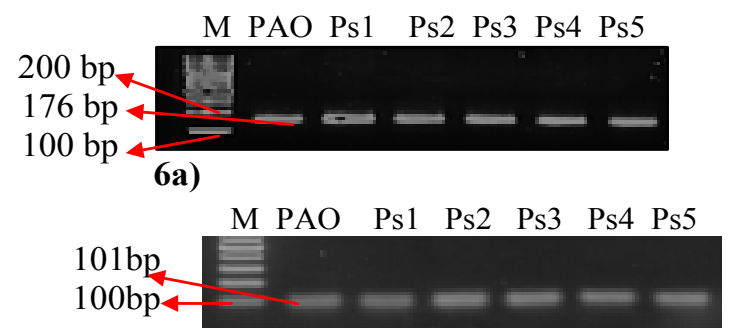

6c)

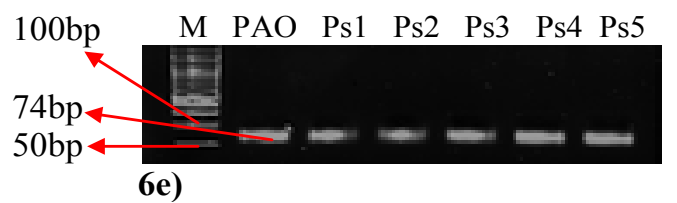

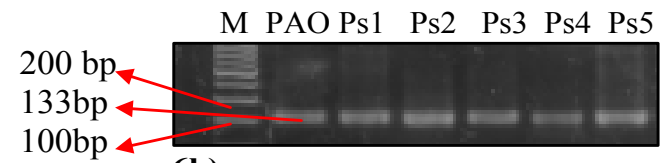

6b)
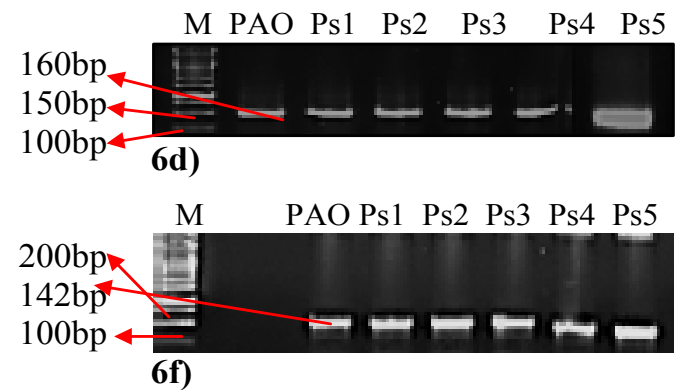

Figure 6. Agarose gel electrophoresis of (a) lasI amplicon (176bp), (b) las $R$ amplicon (133bp), (c) rhlI amplicon (101bp), (d) rhlR amplicon (160bp), (e) pqsA amplicon (74bp) and (f) $p q s R$ amplicon (142bp). All the tested PCR products (amplified genes) were detected using $1.5 \%$ agarose gel stained with ethidium bromide. Lane $1(\mathrm{M})$ : represent DNA ladder.

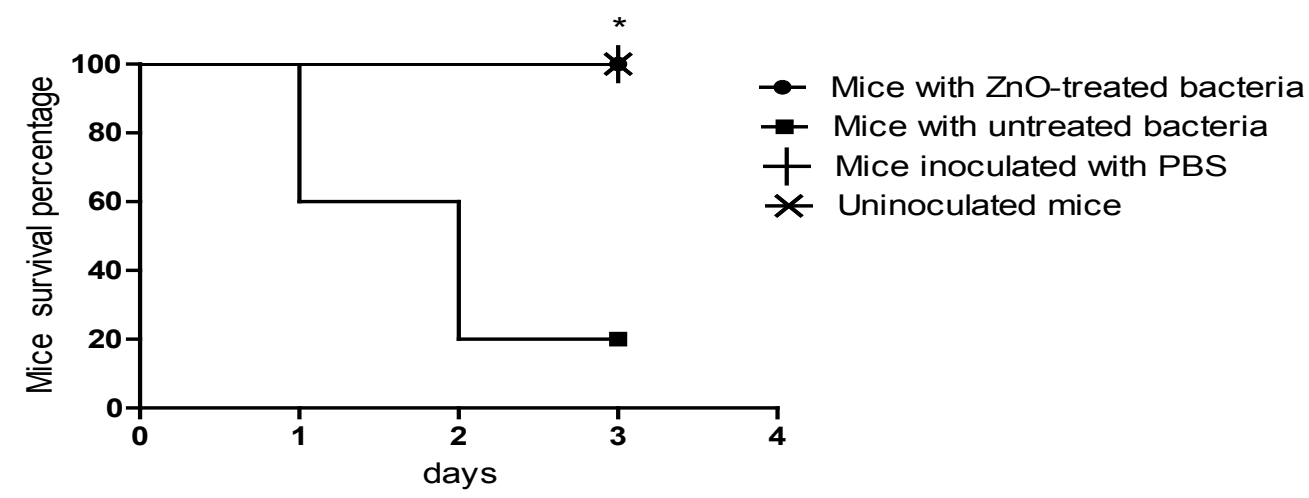

Figure 7. Survival rate was significantly reduced in mice injected with untreated bacteria in comparison to $\mathrm{ZnO}$-treated bacteria and control groups. Mice survival was monitored every day for 3 days and plotted using Kaplan-Meier method. ZnO-treated $P$ s. aeruginosa killed significantly fewer mice as compared to untreated bacteria and (n=10 mice in each group). ${ }^{*}$, significant $P<0.001$.

\section{Discussion}

Ps. aeruginosa has become a principal etiologic agent of nosocomial infections which necessitates the urgent and efficient application of proper infection control policies to combat its spread. It shows both natural resistance and acquired multi-drug resistance to antimicrobial agents bydifferentmechanisms ${ }^{21}$. As an alternative strategy to antimicrobial therapy, targeting of QS has become an attractive option due to its involvement in regulating virulence factors production and pathogenesis in Ps. aeruginosa ${ }^{22}$.
Anti-virulence therapy (as QS inhibitors) would be valuable in the management of microbial diseases due to the lack of pressures affecting bacterial growth upon using anti-virulence agents and so microbial resistance against them is not expected ${ }^{18}$.

In the present study, $\mathrm{ZnO}$ inhibited the growth of all the tested Pseudomonas isolates at $8 \mathrm{mg} / \mathrm{ml}$. Testing the effect of $1 / 4$ MIC of $\mathrm{ZnO}$ nanoparticles $(2 \mathrm{mg} / \mathrm{ml})$ on microbial growth revealed the absence of statistically signifi- 
cant difference between both $\mathrm{ZnO}$-treated and untreated cultures. As a result, any possible effect on QS is not due to adverse impact on bacterial viability and growth. Instead, it may be attributed to disrupting essential bacterial functions.

Ps. aeruginosa produces an arsenal of virulence factors including pyocyanin, pyoverdin, proteases, elastase and rhamnolipids which take partinestablishing infections and making the dissemination and invasion of hosttissues easier ${ }^{23}$. Recently, nanotechnology has been used to develop new nanoparticles that can target QS and virulence factors ${ }^{24-25}$.

In the current study, $\mathrm{ZnO}$ nanoparticles at $1 / 4 \mathrm{MIC}$ showed a potent inhibitory effect on the production ofrhamnolipids,pyocyanin, pyoverdin, hemolysins, elastase and proteases. In accordance with our data,Singh et $\mathrm{al}^{26}$ reported that another type of metal nanoparticles, silver nanoparticles, at sub-MIC exhibited a remarkable reduction in production of proteases, elastase, pyocyanin and rhamnolipids.

LasI/R and rhlI/R are two principle QS systems that regulate virulence genes in Ps. aeruginosa. LasI andrhlI synthases are responsible for the production of C12-AHL and C4-AHL autoinducers, respectively. At a threshold concentration of autoinducers, C12-AHL binds with lasR and induces the expression of genes control production of elastase, exotoxin and proteases and also activates the rhlI/R system. In addition, C4-AHL binds with rhlR andplays role in controlling the expression of genes encoding production of elastase, and pyocyanin. IflasI/R and $\mathrm{rhlI} / \mathrm{R}$ are interrupted, virulence factors will be inhibit$\mathrm{ed}^{27-28}$.

To further explore the potential quorum quenching effect of $\mathrm{ZnO}$ nanoparticles, relative expression of QS-regulatory genes that controlvirulence factors in Ps. aeruginosa was examined using qRT-PCR.Importantly, $\mathrm{ZnO}$ nanoparticles significantly down-regulate the relative expression of QS regulatory genes, lasI, lasR, rhlI, rhlR, pqsA and pqsRwhich confirm the phenotypic results. Similarly, it was proved by Singh et $\mathrm{al}^{26}$ that silver nanoparticles down-regulated the expression of lasI, lasR, rhlI and rhlR at the molecular level by inhibiting lasR and rhlR. $\mathrm{ZnO}$ nanoparticles effect might be similar to that of silver nanoparticles by inhibiting both lasR and rhlR resulting in disruption of QS circuits with subsequent inhibition of virulence factors production. The molecular basis and full mechanism of nanoparticles impact as quorum sensing inhibitor need more investigations in the future.

For more confirmation, the effect of $\mathrm{ZnO}$ nanoparticles on Ps. aeruginosa pathogenesis was determined in vivo. Interestingly, a significant increase in the survival rate of mice injected with $\mathrm{ZnO}$-treated isolates was found in comparison to those injected with untreated ones. Previous reports also showed the protective effect of QSinhibitors against bacterial pathogenesisin mice injected with Ps. aeruginosa. This was reported for gingerol ${ }^{19}$ and polyphenolic compounds of honey ${ }^{29}$. Our collective phenotypic, genotypic and in vivo results strongly potentiate the potential use of $\mathrm{ZnO}$ nanoparticles as a powerful QS inhibitor in Ps. aeruginosa.

\section{Conclusion}

The spread of MDR strains of Ps. aeruginosa is of a particular concern causing healthcare-associated infections and increasing the challenge both in the clinical treatment of patients and in the prevention of the cross-transmission of this problematic pathogen. QS controls the production of many of virulence factors in Ps. aeruginosa and plays an essential role in antimicrobial resistance. $\mathrm{ZnO}$ nanoparticles is a promising QS inhibitor and anti-virulence compound that can be used as an adjunct for the treatment of Ps. aeruginosa infections such as burns and surgical wound infectionsmainly those caused by MDR isolates.

\section{Acknowledgment}

We would like to thank members of Medical Research Center, Ain Shams University, Cairo, Egypt, for providing us with mice and for their help in mice infection model experiment.

\section{Conflict of interest}

The authors declare that they have no conflict of interest.

\section{List of abbreviations}

$\mathrm{AK}=$ amikacin, $\mathrm{ATM}=$ aztreonam, $\mathrm{CAZ}=$ ceftazidime, $\mathrm{CIP}=$ ciprofloxacin, $\mathrm{CT}=$ colistin sulfate, $\mathrm{CN}=$ gentamicin, $\mathrm{C} 4-\mathrm{HSL}=$ butyryl-homoserine lactone, $\mathrm{C} 12-\mathrm{HSL}=\mathrm{Ox}-$ ododecanoyl-homoserine lactone, CLSI = Clinical Laboratory and Standards Institute,ECR = Elastin congo red, $\mathrm{FEP}=$ cefepime, $\mathrm{IPM}=$ imipenem, $\mathrm{LB}=$ Luria-Bertani, $\mathrm{LEV}=$ levofloxacin, $\mathrm{MDR}=$ multi-drug resistant, $\mathrm{MIC}=$ 
minimum inhibitory concentration, $\mathrm{OD}=$ optical density, $\mathrm{PBS}=$ phosphate-buffered saline, $\mathrm{PRL}=$ piperacillin, $\mathrm{Ps}=$ Pseudomonas, PQS=Pseudomonas quinolone-based intracellular signal, $\mathrm{QS}=$ quorum sensing, $\mathrm{SDS}=$ Sodium dodecyl sulfate, and $\mathrm{ZnO}=\mathrm{Zinc}$ oxide.

\section{References}

1. Sangani MH, MoghaddamMN, Forghanifard MM.Inhibitory effect of zinc oxide nanoparticles on Pseudomonas aeruginosa biofilm formation. Nanomedical Journal. 2015;2(2): 121-128.

2. Fernebro J. Fighting bacterial infections: future treatment options. Drug Resistance Updates. 2011; 14: 125-139. 3. Antunes LC, Ferreira RB, Buckner MM, Finlay BB. Quorum sensing in bacterial virulence. Microbiology. 2010;156: 2271-2282.

4. Davies DG, Parsek MR, Pearson JP, Iglewski BH, Costerton JW, Greenberg EP. The involvement of cellto-cell signals in the development of a bacterial biofilm. Science. 1998; 280: 295-298.

5. Fuqua C, Parsek MR, Greenberg EP.Regulation of gene expression by cell-to-cell communication: acyl-homoserine lactone quorum sensing. Annual Reviews of Genetics. 2001; 35: 439-468.

6. Häussler S. Multicellular signalling and growth of $P s$. aeruginosa. International Journal of Medical Microbiology. 2010; 300: 544-548.

7. Garcia-Lara B, Saucedo-Mora MA, Roldan-SanchezJA, Perez-EretzaB, Ramasamy M, Lee J, et al. Inhibition of quorum-sensing-dependent virulence factorsand biofilm formation of clinical and environmental Pseudomonas aeruginosa strains by $\mathrm{ZnO}$ nanoparticles. Letters in Applied Microbiology. 2015; 61: 299-305.

8. Aysa NH, SalmanHD. Antibacterial activity of modified zinc oxide nanoparticles against Ps. aeruginosa isolates of burn infections. World Scientific News. 2016; 33: 1-14.

9. Pati R, Mehta RK, Mohanty S, Padhi A, Sengupta M, Vaseeharan B, et al. Topical application of zinc oxide nanoparticles reduces bacterial skin infection in mice and exhibits antibacterial activity by inducing oxidative stress response and cell membrane disintegration in macrophages. Nanomedicine.2014; 10(6): 1195-208.

10. Koneman EW, Allen SD, Janda WM, Scheckenberger PC, Winn WC. Color atlas and textbook of diagnostic microbiology 6th ed. Philadelphia, USA, Lippincott, 2006.

11. Clinical and Laboratory Standards Institute. Approved standard, CLSI document M100-S-25, Vol. 35 No. 3. Wayne, PA, USA, 2015.
12. Nalca Y, Jansch L, Bredenbruch F,Geffers R, Buer J, Häussler S. Quorum-sensing antagonistic activities of azithromycin in Pseudomonas aeruginosa PAO1, a global approach. Antimicrobial Agents and Chemotherapy. 2006; 50: 1680-1688.

13. Morikawa M, Hirataa y, Imanaka T. A study on the structure-function relationship of lipopeptide biosurfactants. Biochimica et Biophysica Acta. 2000; 1488(3): 211-218. 14. Essar DW, Eberly L, Hadero A, Crawford IP. Identification and characterization of genes for a second anthranilate synthase in Pseudomonas aeruginosa: interchangeability of the two anthranilate synthases and evolutionary implications. Journal of Bacteriology. 1990; 172: 884-900.

15. Cox CD, AdamsP. Siderophore activity of pyoverdin for Pseudomonas aeruginosa. Infection and Immunity. 1985;48,130-138.

16. Dacheux D, Goure J, Chabert J, Usson Y, Attree I.Pore-forming activity of type III system-secreted proteins leads to oncosis of Pseudomonas aeruginosa-infected macrophages. Molecular Microbiology. 2001; 40: 76-85.

17. Ohman DE, Cryz SJ, Iglewski BH. Isolation and characterization of a Pseudomonas aeruginosa PAO1 mutant that produces altered elastase. Journal of Bacteriology. 1980; 142: 836-884.

18. El-Mowafy SA, Shaaban M, Abd El-Galil KH. Sodium ascorbate as a quorum sensing inhibitor of Psendomonas aeruginosa. Journal of Applied Microbiology. 2014;117: 1388-1399.

19. Livak KJ, Schmittgen TD. Analysis of relative gene expression data using real-time quantitative PCR and the 2- $\Delta \Delta$ CT Method. Methods. 2001; 25: 402-8.

20. Kim H, Lee S, Byun Y, Park H. 6-Gingerol reduces Pseudomonas aeruginosa biofilm formation and virulence via quorum sensing inhibition. Scientific Reports. 2015; 5: 8656. 21.Verma U, Kulshreshtha S, Khatri PK.MDR Pseudomonas aeruginosa in Nosocomial Infection: Burden in ICU and Burn Units of a Tertiary Care Hospital. International Journal of Current Microbiology and Applied Science. 2018; 7(1): 1267-1274.

22. Zhao T, Liu Y. N-acetylcysteine inhibit biofilms produced by Psendomonas aeruginosa. BMC Microbiology. 2010; 10: 140 .

23.Gellatly L, Hancock, W. Pseudomonas aeruginosa, new insights into pathogenesis and host defenses. Pathogens and Disease. 2013; 67: 159-173.

24. Kalishwaralal K, BarathManiKanth S, Pandian SR, Deepak V, Gurunathan S. Silver nanoparticles impede the biofilm formation by Pseudomonas aeruginosa and Staphylo- 
coccus epidermidis. Colloids Surfaces B Biointerfaces. 2010; 79: 340-344.

25. Kumar CG, Mamidyala SK. Extracellular synthesis of silver nanoparticles using culture supernatant of Psendomonas aeruginosa. Colloids Surfaces B Biointerfaces. 2011; 84:462-466.

26. Singh BR, Singh BN, Singh A, Khan W, Naqvi AH, Singh HB.Mycofabricated biosilver nanoparticles interrupt Pseudomonas aeruginosa quorum sensing systems. Scientific Reports. 2015; 5:13719.

27. ParsekMR, Val DL, Hanzelka BL, Val DL, Hanzelka BL, CronanJr JE, et al. Acyl-homoserine lactone quorum sensing signal generation. Proceedings of the National Academy of Sciences of the United States of America. 1999; 96:43604365.

28. Parsador L, Cook JM, Gambello MJ, Rust L, Iglewski BH. Expression of Pseudomonas aeruginosa virulence genes requires cell-to-cell communication. Science. 1993; 260:1127-1130.

29. Prateeksha, Singh BR, Shoeb M, Sharma S,Naqvi AH, GuptaVK, et al. (2017) Scaffold of selenium nanovectors and honey phytochemicals for inhibition of Pseudomonas aeruginosa quorum sensing and biofilm formation. Frontiers in Cellular and Infection Microbiology. 2017; 7: 1-14. 